\title{
Speleothem synthesis and analysis working group
}

\author{
Laia Comas-Bru', M. Deininger ${ }^{1}$, S. Harrison ${ }^{2,3}$, M. Bar-Matthews ${ }^{4}$, A. Baker ${ }^{5}$, W. Duan ${ }^{6}$ and N. Stríkis ${ }^{7}$
}

Speleothems are secondary cave deposits formed mostly from inorganic calcium carbonate $\left(\mathrm{CaCO}_{3}\right)$. Deposits formed from drip ping water are called stalagmites (growing up from the ground) or stalactites (growing down from the roof). Speleothems are useful paleoclimate archives as they preserve some aspects of the water chemical composition, providing information from the overlying climate, vegetation and soil. These climate archives are well distributed worldwide and are valuable sources for regional climate reconstructions and allow intra- and intercontinental comparisons of past climate changes. In addition, due to the high precision of uranium-series dating, speleothems provide opportunities to trace leads and lags of global climate events facilitating to uncover climate dynamics.

The different types of measurements made on speleothems, including the stable isotopes of oxygen and carbon $\left(\delta^{18} \mathrm{O}, \delta^{13} \mathrm{C}\right)$, annual growth rate variations and various trace elements concentrations, give a wealth of information on past changes in the hydrological cycle, changes in atmospheric composition and the local environment. Significant past climate variations recorded in speleothems include shifts of the Intertropical Convergence Zone, variations of the North Atlantic Oscillation, glacialinterglacial transitions and millennial-scale variability of tropical atmospheric circulation in response to Dansgaard-Oeschger cycles, as well as climate-related migrations of the large Saharo-Arabian Desert and how they enabled migration of humans out of Africa. Speleothems, therefore, provide an opportunity to assess changes in mean climate and in climate variability on various spatial and temporal scales.

Although more than 400 speleothem records have been published over the last decades as a source of climate reconstruction (70\% of which after the year 2007; Source: Web of Science), there have been only limited attempts to synthesize speleothem data. Such a synthesis could be useful not only for exploring past climate changes but also for evaluating state-of-the-art climate models that explicitly simulate water and carbon.

Since the understanding of past climate variability provides a crucial benchmark reference for current and predicted climate change, the recently launched SISAL (Speleothem Isotopes Synthesis and AnaLysis) working group will bring together speleothem scientists, speleothem-process modelers and climate modelers to develop a global-scale database of speleothem isotopic data. This synthesis must include an assessment of the quality of the records, including their reliability and interpretation, and this requires community-wide involvement.

SISAL's kick-off workshop took place in June 2017 at University College Dublin, Ireland, and served to discuss, amongst other things, the structure of the SISAL database and the key scientific questions that we would like to address with it. To feed into these discussions, our focus in the last few months has been on identifying the status of speleothem-based paleoclimate reconstructions

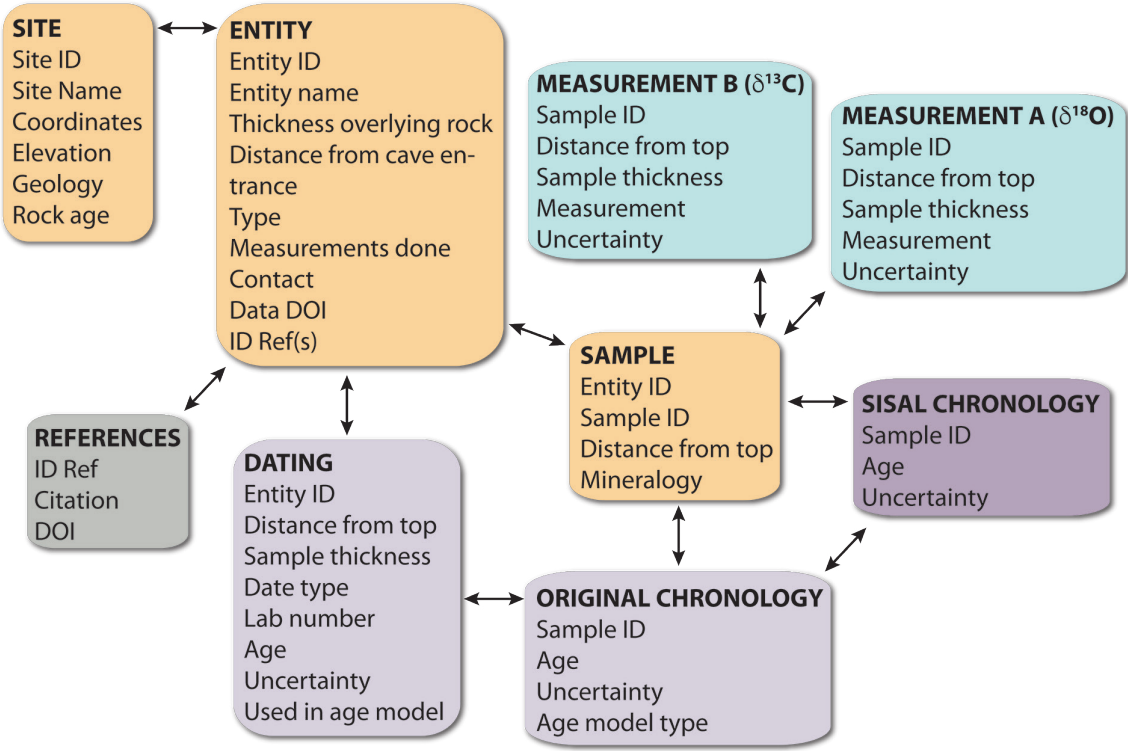

Figure 1: SISAL database structure that seeks to maximize the amount of information available for quality control and standardization of individual records. globally and on creating a preliminary version of the database (Fig. 1).

\section{Upcoming activities}

Although much of the SISAL community interaction will be virtual, further workshops are already being planned for the next years. Each of these will focus on different analyses of the speleothem database.

Our 2nd workshop, aligned with the PMIP meeting, will be held in Stockholm, Sweden, in September 2017 and will focus on the design of data-model comparisons using the SISAL database (www.pastglobalchanges.org/ calendar/upcoming/127-pages/1711-sisal-2ndwshop-17).

\section{Scientific goals}

Paleoclimate records have a complex response to climatic and non-climatic factors (e.g. attenuation of the precipitation isotopic signal prior to the water reaching the speleothem) and, therefore, they need to be assessed for robustness and coherence between records and between different types of archives (e.g. $\delta^{18} \mathrm{O}$ in ice cores, corals, and tree-ring cellulose) before using them to evaluate the output of climate models. This assessment will be the first concrete task for SISAL.

By encouraging interaction and exchange of information between the speleothem community and climate and speleothem-process modelers, SISAL aims to develop novel ways to compare speleothem records with the CMIP6-PMIP4 simulations of the Last Glacial Maximum (21 ka), mid-Holocene (6 ka) and Last Millennium (850-1850 CE).

Visit the SISAL website at:

http://pastglobalchanges.org/ini/wg/sisal/intro and sign up to our mailing list, or follow us on Twitter (@SISAL_wg) to keep up to date with our activities.

\section{AFFILIATIONS}

'School of Earth Sciences, University College Dublin Ireland

${ }^{2}$ School of Archaeology, Geography and Environmental Sciences, University of Reading, UK ${ }^{3}$ Centre for Past Climate Change, University of Reading, UK

Geological Survey of Israel, Jerusalem, Israel Connected Waters Initiative Research Centre University of New South Wales, Sydney, Australia Institute of Geology and Geophysics, Chinese Academy of Sciences, Beijing, China Institute of Chemistry, Fluminense Federal university, Niteroi, Brazil

\section{CONTACT}

aia Comas-Bru: laia.comasbru@ucd.ie 